\title{
MENGKONSTRUKSI DIRECT PRODUCT NEAR RING DAN SMARANDACHE NEAR RING
}

\author{
Rizky Muhammad Bagas ${ }^{1}$, Titi Udjiani SRRM ${ }^{2}$, Harjito $^{3}$ \\ ${ }^{1,2,3}$ Departemen Matematika, Fakultas Sains dan Matematika, Universitas Diponegoro. \\ Email : ${ }^{1}$ rizkymuh.bagas@yahoo.com.
}

\begin{abstract}
If we have two arbitrary non empty sets ,then their cartesian product can be constructed. Cartesian products of two sets can be generalized into $n$ number of sets. It has been found that if the algebraic structure of groups and rings are seen as any set, then the phenomenon of cartesian products of sets can be extended to groups and rings. Direct products of groups and rings can be obtained by adding binary operations to the cartesian product. This paper answers the question of whether the direct product phenomenon of groups and rings can also be extended at the near ring and Smarandache near ring ?. The method in this paper is by following the method in groups and rings, namely by seen that near ring and Smarandache near ring as a set and then build their cartesian products. Next, the binary operations is adding to the cartesian products that have been obtained to build the direct product definitions of near ring and near ring Smarandache.
\end{abstract}

Kata Kunci: Cartesian, direct, product, near-ring, Smarandache

\begin{abstract}
Abstrak. Jika diberikan dua buah himpunan sebarang yang tidak kosong, maka dapat dibangun cartesian productnya yaitu suatu himpunan yang elemennya merupakan pasangan terurut dari himpunan himpunan tersebut. Cartesian produk dari dua himpunan dapat diperumum untuk sejumlah $n$ himpunan. Telah diperoleh bahwa jika struktur aljabar grup dan ring dipandang sebagai himpunan, maka fenomena cartesian product pada himpunan sebarang dapat diperluas pada grup dan ring. Direct product dari grup dan ring dapat diperoleh dengan menambahkan operasi biner pada cartesian productnya Tulisan ini menjawab pertanyaan bahwa apakah fenomena direct product dari grup dan ring juga dapat diperluas pada struktur aljabar near ring dan near ring Smarandache. Metode yang digunakan dengan mengikuti metode pada grup dan ring, yaitu dengan memandang struktur aljabar near ring dan dan near ring Smarandache sebagai suatu himpunan dan membangun cartesian product dari near ring dan near ring Smarandache. Selanjutnya menambahkan operasi biner pada cartesian product yang telah diperoleh untuk membangun definisi direct product pada near ring dan near ring Smarandache.
\end{abstract}

Kata Kunci: Cartesian, direct, product, near-ring, Smarandache

\section{PENDAHULUAN}

Linda dan Jimmie Gilbert [ 7], menjelaskan bahwa jika diketahui himpunan tidak kosong $A_{1}$ dan $A_{2}$, maka Cartesian product dari $A_{1}$ dan $A_{2}$ didefinisikan sebagai :

$$
A_{1} \times A_{2}=\left\{\left(a_{1}, a_{2}\right) \mid a_{1} \in A_{1}, a_{2} \in A_{2}\right\} \text {. }
$$


Cartesian product dari himpunan $A_{1}$ dan $A_{2}$ adalah himpunan yang elemen elemennya adalah pasangan terurut dari elemen anggota $A_{1}$ dan $A_{2}$. Pada setiap pasangan, memuat komponen pertama yang merupakan elemen anggota $A_{1}$ dan komponen ke kedua adalah elemen anggota $A_{2}$. Urutan komponen diperhatikan, artinya $\left(a_{1}, a_{2}\right)=\left(b_{1}, b_{2}\right)$ jika dan hanya jika $a_{1}=b_{1}$ dan $a_{2}=b_{2}$ untuk setiap $a_{1}, b_{1} \in A_{1}$ dan $a_{2}, b_{2} \in A_{2}$.

Menurut Thomas W. dan Judson Stephen F. [8], Cartesian product pada dua buah himpunan dapat diperumum pada sejumlah berhingga himpunan. Jika diberikan sejumlah $n \in \mathbb{Z}$ himpunan $A_{1}, A_{2}, \ldots, A_{n}$ maka

$$
A_{1} \times A_{2} \times \ldots \times A_{n}=\left\{\left(a_{1}, a_{2}, \ldots, a_{n}\right) \mid a_{1} \in A_{1}, a_{2} \in A_{2}, \ldots, a_{n} \in A_{n}\right\} .
$$

Grup merupakan struktur aljabar yang memiliki sebuah operasi biner dan memenuhi sifat-sifat tertentu. Definisi grup oleh Adkins, dkk [1], didefinisikan sebagai berikut :

Definisi 1. Grup $(G, *)$ adalah suatu himpunan tak kosong $G$ dengan operasi biner “ * “ : $G \times G \rightarrow G$ yang memenuhi aksioma-aksioma berikut:

i. Operasi biner * bersifat asosiatif, artinya $a *(b * c)=(a * b) * c$ untuk setiap $a, b, c \in G$

ii. Himpunan $G$ memiliki elemen identitas artinya, terdapat $e \in G$ sedemikian hingga untuk setiap $a \in G$ berlaku. $a * e=e * a=a$

iii. Setiap elemen di $G$ memiliki invers di $G$, artinya untuk setiap $a \in G$ terdapat $b \in G$ sedemikian hingga $a * b=b * a=e$

Dengan memandang struktur aljabar grup $G$ sebagai himpunan, Adkins, dkk, memperluas definisi cartesian product dari himpunan ke grup dan membangun direct product dari grup seperti yang disampaikan pada Definisi 2 sebagai berikut :

Definisi 2. Diberikan $G_{1}$ dan $G_{2}$ adalah grup. Direct product dari $G_{1}$ dan $G_{2}$, dinotasikan $G_{1}$ x $G_{2}$ adalah Cartesian product dari $G_{1}$ x $G_{2}$ dengan operasi biner “ * " yang didefinisikan sebagai $\left(g_{1}, g_{2}\right) *\left(h_{1}, h_{2}\right)=\left(g_{1} * h_{1}, g_{2} * h_{2}\right)$ untuk setiap $\left(g_{1}, g_{2}\right),\left(h_{1}, h_{2}\right) \in G_{1} \times G_{2}$.

Selain struktur aljabar grup, pada bidang aljabar juga dikenal struktur aljabar ring. Menurut Dummit, dkk [2], ring didefinisikan sebagi berikut. 
Definisi 3. Sebuah ring $R$ adalah himpunan dengan dua operasi biner "+" dan "." (disebut penjumlahan dan pergandaan) yang memenuhi aksioma-aksioma berikut:

i. $(R,+)$ adalah grup abelian,

ii. $(R, \cdot)$ bersifat assosiatif yaitu $a \cdot(b \cdot c)=(a \cdot b) \cdot c$ untuk setiap $a, b, c \in R$,

iii. Berlaku hukum distributif di $R$, artinya untuk setiap $a, b, c \in R$ berlaku

$$
(a+b) \cdot c=(a \cdot c)+(b \cdot c) \text { dan } a \cdot(b+c)=(a \cdot b)+(a \cdot c) .
$$

Seperti halnya Adkins, peneliti lain yaitu Doer, dkk [3] mendefinisikan pengertian direct product pada ring sebagai berikut :

Definisi 4. Diberikan $\left\{R_{i}\right\}$ adalah keluarga ring dimana $i=1,2, \ldots, n$. Direct product dari

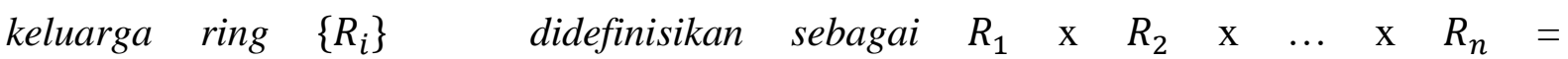
$\left\{\left(a_{1}, a_{2}, \ldots, a_{n}\right) \mid a_{1} \in R_{1}, a_{2} \in R_{2}, \ldots, a_{n} \in R_{n}\right\}$ dengan operasi penjumlahan dan pergandaan pada $R_{1} \times R_{2} \times \ldots \times R_{n}$ didefinisakan sebagai :

$$
\begin{aligned}
& \left(a_{1}, a_{2}, \ldots, a_{n}\right)+\left(b_{1}, b_{2}, \ldots, b_{n}\right)=\left(a_{1}+b_{1}, a_{2}+b_{2}, \ldots, a_{n}+b_{n}\right) \\
& \left(a_{1}, a_{2}, \ldots, a_{n}\right) .\left(b_{1}, b_{2}, \ldots, b_{n}\right)=\left(a_{1} . b_{1}, a_{2} . b_{2}, \ldots, a_{n} . b_{n}\right)
\end{aligned}
$$

untuk setiap $\left(a_{1}, a_{2}, \ldots, a_{n}\right),\left(b_{1}, b_{2}, \ldots, b_{n}\right) \in R_{1} \times R_{2} \times \ldots \times R_{n}$.

Selain grup dan ring, juga dikenal struktur aljabar near ring dan Smarandache near ring, sehingga wajar jika muncul pertanyaan apakah konsep direct product yang dimiliki oleh grup dan ring juga dapat dimiliki oleh near ring dan Smarandache near ring.

\section{PEMBAHASAN}

Salah satu struktur aljabar yang merupakan bentuk khusus ring adalah near ring. Dengan mengabaikan sifat komutatif terhadap operasi penjumlahan dan sifat distributif kiri pada ring, Satyanarayana dkk [4] mendefinisikan near ring.

Definisi 5. Himpunan tak kosong $N$ yang dilengkapi dengan operasi biner "+" dan “.” disebut Near-ring jika:

i. Himpunan $N$ dengan operasi penjumlahan "+" memenuhi syarat grup.

ii. Himpunan $N$ dengan operasi pergandaan "." memenuhi syarat semigrup.

iii. Untuk setiap $p, q, r \in N$, berlaku $(p+q) \cdot r=(p \cdot r)+(q \cdot r)$. 
Dimotivasi oleh Linda serta Thomas W, dkk dan dengan memandang struktur aljabar near ring sebagai himpunan, maka dapat diperoleh caretesian product dari near ring $\left(N_{1},+_{1},{ }_{1}\right)$ dan $\left(N_{2},+_{2},{ }_{2}\right)$ sebagai berikut :

$$
N_{1} \times N_{2}=\left\{\left(n_{1}, n_{2},\right) \mid n_{i} \in N_{i}, i=1,2\right\}
$$

Selanjutnya pada $N_{1} \times N_{2}$ didefinisikan operasi penjumlahan " $+_{N}$ " sebagai berikut :

$$
\left(p_{1}, p_{2}\right)+_{N}\left(q_{1}, q_{2}\right)=\left(p_{1}+_{1} q_{1}, p_{2}+_{2} q_{2}\right)
$$

untuk setiap $\left(p_{1}, p_{2}\right),\left(q_{1}, q_{2}\right) \in N_{1} \times N_{2}$. Operasi “ $+_{N}$ " pada $N_{1}$ x $N_{2}$ merupakan operasi biner, karena dengan menggunakan sifat tertutup operasi " $+_{1}$ " pada $N_{1}$ dan operasi " $+_{2}$ " pada $N_{2}$ dijamin bahwa $p_{1}+{ }_{1} q_{1} \in N_{1}$ dan $p_{2}+_{2} q_{2} \in N_{2}$.

Telah diketahui bahwa kesamaan dua buah elemen di $N_{1}$ x $N_{2}$ diberikan dengan $\left(p_{1}, p_{2}\right)=$ $\left(q_{1}, q_{2}\right)$ jika dan hanya jika $p_{1}=q_{1}$ dan $p_{2}=q_{2}$ untuk setiap $\left(p_{1}, p_{2}\right),\left(q_{1}, q_{2}\right) \in N_{1} \times N_{2}$.

Berikutnya dengan menggunakan sifat kesamaan dua buah elemen dan definisi operasi penjumlahan di $N_{1} \times N_{2}$ diperoleh bahwa jika $\left(p_{1}, p_{2}\right)=\left(q_{1}, q_{2}\right)$ dan $\left(r_{1}, r_{2}\right),=\left(s_{1}, s_{2}\right)$, maka $\left(p_{1}, p_{2}\right)+_{N}\left(r_{1}, r_{2}\right)=\left(p_{1}+{ }_{1} r_{1}, p_{2}+{ }_{2} r_{2}\right)=\left(q_{1}+{ }_{1} s_{1}, q_{2}+_{2} s_{2}\right)=$ $\left(q_{1}, q_{2}\right)+_{N}\left(s_{1}, s_{2}\right)$ untuk setiap $\left(p_{1}, p_{2}\right),\left(q_{1}, q_{2}\right),\left(r_{1}, r_{2}\right),\left(s_{1}, s_{2}\right) \in N_{1} \times N_{2}$.

Selain operasi penjumlahan, pada $N_{1}$ x $N_{2}$ juga didefinisikan operasi perkalian " " $N$ " sebagai berikut :

$$
\left(p_{1}, p_{2}\right) \cdot{ }_{N}\left(q_{1}, q_{2}\right)=\left(p_{1} \cdot{ }_{1} q_{1}, p_{2} \cdot{ }_{2} q_{2}\right)
$$

untuk setiap $\left(p_{1}, p_{2}\right),\left(q_{1}, q_{2}\right) \in N_{1} \times N_{2}$. Operasi “ " $N$ " pada $N_{1} \times N_{2}$ merupakan operasi biner, karena dengan menggunakan sifat tertutup operasi “ . 1 " pada $N_{1}$ dan operasi " .2 " pada $N_{2}$ dijamin bahwa $p_{1} \cdot{ }_{1} q_{1} \in N_{1}$ dan $p_{2}{ }_{2} q_{2} \in N_{2}$. Dengan menggunakan prinsip kesamaan dua buah elemen dan definisi operasi perkalian " ${ }_{N}$ " di $N_{1} \times N_{2}$ diperoleh bahwa jika $\left(p_{1}, p_{2}\right)=\left(q_{1}, q_{2}\right)$ dan $\left(r_{1}, r_{2}\right),=\left(s_{1}, s_{2}\right)$, maka $\left(p_{1}, p_{2}\right){ }_{N}\left(r_{1}, r_{2}\right)=\left(p_{1}{ }_{1} r_{1}, p_{2}{ }_{2} r_{2}\right)=$ $\left(q_{1} \cdot{ }_{1} s_{1}, q_{2} \cdot{ }_{2} s_{2}\right)=\left(q_{1}, q_{2}\right){ }_{N}\left(s_{1}, s_{2}\right)$ untuk setiap $\left(p_{1}, p_{2}\right),\left(q_{1}, q_{2}\right),\left(r_{1}, r_{2}\right),\left(s_{1}, s_{2}\right) \in N_{1}$ x $N_{2}$.

Sampai disini dapat ditunjukkan bahwa definsi operasi penjumlahan " $+_{N}$ " dan perkalian " ${ }_{N}$ " pada $N_{1} \times N_{2}$ dapat dioperasionalkan dengan baik ( well defined). Himpunan $N_{1}$ x $N_{2}$ yang dilengkapi dengan operasi “ $+_{N}$ " dan “ " $N$ " selanjutnya disebut direct product dari $N_{1} \times N_{2}$. Fenomema yang dimiliki $N_{1} \times N_{2}$, oleh Kandasamy [6] diperumum untuk sejumlah $n$ near ring melalui Definisi 6 sebagai berikut : 
Definisi 6. Diberikan $\left\{\left(N_{i},+_{i},{ }_{i}\right)\right\}$ adalah keluarga near-ring dengan $i \in I$ dan I adalah himpunan indeks. Direct product dari $N_{1} \times N_{2}$ x $\ldots$ x $N_{n}$ didefinisikan sebagai himpunan

$$
N_{1} \times N_{2} \times \ldots \times N_{n}=\left\{\left(n_{1}, n_{2}, \ldots, n_{n}\right) \mid n_{i} \in N_{i}, i \in I\right\}
$$

yang dilengkapi dengan operasi penjumlahan " $+_{N}$ " dan operasi pergandaan " ${ }_{N}$ " pada $N_{1}$ x $N_{2} \times \ldots \times N_{n}$ sebagai berikut

$$
\left(p_{1}, p_{2}, \ldots, p_{n}\right)+_{N}\left(q_{1}, q_{2}, \ldots, q_{n}\right)=\left(p_{1}+_{1} q_{1}, p_{2}+_{2} q_{2}, \ldots, p_{n}+_{n} q_{n}\right)
$$

dan

$$
\left(p_{1}, p_{2}, \ldots, p_{n}\right){ }_{N} \cdot\left(q_{1}, q_{2}, \ldots, q_{n}\right)=\left(p_{1} \cdot \cdot_{1} q_{1}, p_{2} \cdot_{2} q_{2}, \ldots, p_{n} \cdot{ }_{n} q_{n}\right)
$$

untuk setiap $\left(p_{1}, p_{2}, \ldots, p_{n}\right),\left(q_{1}, q_{2}, \ldots, q_{n}\right) \in N_{1} \times N_{2} \times \ldots \times N_{n}$

Tidak setiap near ring memuat elemen satuan dan elemen tidak nolnya memiliki invers. Selanjutnya Patty, dkk [5], menyampaikan Definisi 7 dibawah ini :

Definisi 7. Near-ring $(N,+, \cdot)$ disebut near-field, jika memenuhi

(a) $(N,+, \cdot)$ adalah near-ring dengan elemen satuan $e$.

(b) Setiap elemen tak nol di $N$ memiliki invers terhadap operasi pergandaan ". " di N.

Untuk setiap $a \neq 0 \in N$, terdapat $a^{-1} \in N$ sehingga $a \cdot a^{-1}=a^{-1} \cdot a=e$.

Struktur aljabar near ring adalah suatu himpunan, sehingga pasti memiliki himpunan bagian. Paling tidak himpunan bagiannya adalah dirinya sendiri. Berdasarkan beberapa contoh near ring diperoleh bawa terdapat himpunan bagian sejati dari near ring yang membentuk struktur aljabar tertentu. Salah satu near ring yang memiliki sifat demikian dikemukakan oleh Kandasamy [6] melalui Definisi 8 berikut ini :

Definisi 8. Near ring $(N,+, \cdot)$ disebut Smarandache near-ring, jika $(N,+, \cdot)$ memiliki himpunan bagian sejati tak kosong A sehingga $(A,+, \cdot)$ adalah near-field.

Dengan mengingat bahwa Smarandache near ring merupakan kejadian khusus dari near ring dan sifat tertutup terhadap operasi penjumlahan serta perkalian yang dimiliki oleh near ring 
juga dimiliki oleh Smarandache near ring, maka konsep direct product pada near ring oleh Kandasamy [6], diperluas pada Smarandache near ring.

Definisi 9. Diberikan $\left\{\left(\boldsymbol{N}_{\boldsymbol{i}},+_{\boldsymbol{i}},{ }_{\boldsymbol{i}}\right)\right\}$ keluarga dari Smarandache near-ring. Himpunan $D=N_{1} \times \ldots \times N_{r}=\left\{\left(n_{1}, n_{2}, \ldots, n_{r}\right) \mid n_{i} \in N_{i}, i=1,2, \cdots, r\right\}$ beserta operasi penjumlahan " ${ }_{\boldsymbol{D}}$ " dan operasi pergandaan " 'D" yang didefinisikan sebagai berikut

$$
\left(p_{1}, p_{2}, \ldots, p_{n}\right)+_{D}\left(q_{1}, q_{2}, \ldots, q_{n}\right)=\left(p_{1}+_{1} q_{1}, p_{2}+_{2} q_{2}, \ldots, p_{n}+_{n} q_{n}\right)
$$

dan

$$
\left(p_{1}, p_{2}, \ldots, p_{n}\right){ }_{D}\left(q_{1}, q_{2}, \ldots, q_{n}\right)=\left(\begin{array}{lll}
p_{1} \cdot{ }_{1} & q_{1}, p_{2} \cdot{ }_{2} q_{2}, \ldots, p_{n} \cdot_{n} q_{n}
\end{array}\right)
$$

untuk setiap $\left(p_{1}, p_{2}, \ldots, p_{n}\right),\left(q_{1}, q_{2}, \ldots, q_{n}\right) \in N_{1} \times N_{2} \times \ldots \times N_{n}$, disebut direct product dari Smarandache near-ring $\left(N_{i},+_{i},{ }_{i}\right)$.

\section{KESIMPULAN}

Konsep direct product pada struktur aljabar grup dan ring dapat diperluas pada struktur aljabar near ring dan smarandache near ring. Problem yang muncul selanjutnya adalah apakah direct product pada near ring dan smarandache near ring membentuk struktur aljabar tertentu.

\section{REFERENSI}

[1] Adkins, William A, Weintraub, Steven H. 1992. Algebra An Approach Via Module Theory. Springer-Verlag. New York.

[2] Dummit, David S, and Foote, Richard M. 2003. Abstract Algebra, Third Edition. Wiley. USA.

[3] Doer, Al, and Levasseur, Ken. 2018. Applied Discrete Structures, Third Edition. Lulu.com. North California.

[4] Satyanarayana, Bhavanari, and Prasad, Kuncham S. 2013. Near Rings, Fuzzy Ideals, and Graph Theory. CRC Press. USA.

[5] Patty, Henry W. M. 2014. "Hasil Kali Langsung S-Near-Ring dan S-Near-Ring Bebas". Jurnal Barekeng, vol. 8, no. 2, hal. 1-7. Universitas Pattimura. Ambon.

[6] Kandasamy, W.B.V. 2002. Smarandache Near-rings. American Research Press. Rehoboth.

[7] Linda dan Jimmie G, 2009, Elements of Modern Algebra, Seventh Edition Brooks/Cole 10Davis Drive Belmont, USA

[8] Thomas W. Judson Stephen F, 2010, Abstract Algebra Theory and Applications, Austin State University 